\title{
A importância das leituras de livre escolha na formação do leitor
}

\author{
Hilda Gomes Dutra Magalhães \\ Universidade Federal do Tocantins
}

\begin{abstract}
RESUMO: O OBJETIVO DESTE ESTUDO CONSISTE EM REFLETIR, A PARTIR DA TEORIA DO LETRAMENTO LITERÁRIO, SOBRE OS CRITÉRIOS DE SELEÇÃO DE OBRAS, EM SITUAÇÕES NAS QUAIS OS PROFESSORES DÃO AOS ALUNOS LIBERDADE PARA ESCOLHEREM SUAS LEITURAS, TENTANDO COMPREENDER AS VARIÁVEIS ENVOLVIDAS NO PROCESSO E A SUA IMPORTÂNCIA NA FORMAÇÃO DE LEITORES AUTÔNOMOS DE LITERATURA.
\end{abstract}

ABSTRACT: THE AIM OF THIS STUDY IS TO REFLECT, FROM THE THEORY OF LITERACY LITERARY, ABOUT THE CRITERIONS FOR SELECTION OF WORKS, IN SITUATIONS WHERE STUDENTS ARE FREE TO CHOOSE THEIR READINGS, TRY TO UNDERSTAND THE VARIABLES INVOLVED IN THE PROCESS AND ITS IMPORTANCE IN TRAINING OF READERS OF LITERATURE.

PALAVRAS-CHAVE: LITERATURA - LETRAMENTO - ENSINO FUNDAMENTAL KEY-WORDS: LITERATURE - LITERACY - BASIC EDUCATION 
seleção dos textos literários a serem trabalhados no espaço escolar é uma problemática ainda não suficientemente discutida. Problemas como a rejeição aos clássicos pelos alunos, a insuficiência de capacitação dos professores da rede de Ensino Básico em relação ao letramento literário, a insipiente produção científica teórico-prático sobre a questão e a quase que total indiferença da Academia em relação à literatura infanto-juvenil tornam a escolarização da literatura bastante problemática.

Partindo do princípio de que letramento é o "conjunto de práticas socialmente construídas que envolvem a leitura e a escrita, geradas por processos sociais mais amplos, e responsáveis por reforçar ou questionar valores, tradições e formas de distribuição de poder presentes nos contextos sociais" (SOARES, 1998: 98), o nosso objetivo neste artigo é refletir sobre os critérios de seleção de leituras literárias em situações nas quais os professores deixam aos alunos essa prorrogativa, tentando compreender as variáveis envolvidas no processo e a sua importância na formação de leitores autônomos.

Cosson define o ensino da literatura como o "processo de formação de um leitor capaz de dialogar no tempo e no espaço com sua cultura, identificando, adaptando ou construindo um lugar para si mesmo" (COSSON, 2007: 120). Halliday afirma que o letramento literário

consiste fundamentalmente em experienciar o mundo por meio da palavra; a aprendizagem sobre literatura, que envolve conhecimentos de história, teoria e crítica; e a aprendizagem por meio da literatura, nesse caso os saberes e as habilidades que a prática da literatura proporciona aos seus usuários. (citado por COSSON, 2007: 47)

Letramento literário é compreendido também como instrumento para "formar um leitor para quem o texto é objeto de intenso desejo, para quem a leitura é parte indissociável do jeito de ser e de viver" (RANGEL, 2005: 137-138), o que é corroborado por Soares, para quem o letramento literário deve se concretizar através de uma leitura "que se realiza pelo desejo, pela espontaneidade, pela ausência de controles e satisfações devidas" (citada por CORREA, 2005: 72).

Nesta mesma direção, Pereira afirma que 
o letramento literário deve assumir cada vez mais seu caráter de jogo - de ação livre, executada como expressão de imaginação e catarse, articulada nos níveis do possível, do impossível, do vivido e do contingente, sentida como algo que desconstrói os estereótipos do cotidiano e instaura o círculo mágico do prazer. E que, justamente por isso, seja capaz de absorver inteiramente o jogador/leitor expectador, perdendo seu caráter e adereço e passando a funcionar, na pior das hipóteses, como uma necessidade e, no melhor dos mundos, como um desejo. (PEREIRA, 2007: 44)

Como se percebe, as concepções de letramento literário encontram-se em consonância com a complexidade do literário, entretanto, dentre as várias funções que, direta ou indiretamente, a literatura possa desempenhar, a mais nobre e essencial está ligada ao refinamento da sensibilidade. A literatura é arte e, como tal, demanda competências e habilidades ligadas à subjetividade, à criatividade e à sensibilidade, devendo, por isso, ser tratada com métodos e objetivos específicos. Como arte, a literatura exerce uma função formativa não didática, na medida em que

dão uma forma às experiências futuras, fornecendo modelos, recipientes, termos de comparação, esquemas de classificação, escala de valores, paradigmas de beleza: todas, coisas que continuam a valer mesmo que nos recordemos pouco ou nada do livro lido na juventude. (CALVINO, citado por VERSANINI, 2006: 23)

Considerando esta realidade, a primeira demanda do letramento literário é criar o gosto pela leitura, primeiro passo para se instituir o hábito da leitura. Letramento literário significa, neste contexto, a apropriação das competências e habilidades que constituem o hábito de ler, ou seja, o prazer de ler, a capacidade de fruição, a autonomia do leitor na escolha de suas leituras.

Pelo exposto, podemos, portanto, afirmar a existência de pelo menos duas dimensões diferentes do letramento literário, uma voltada para o sentir e outra para o racionalizar o texto, o que nos leva a investir também em diferentes modalidades de leitura. Para Baudelot, Cartier e Detrez, citados por Faria (2005: 15-16), as leituras se classificam em comum e comprometida: na primeira, a relação leitor/obra se dá pela afetividade, ao passo que, na segunda, por um 
esforço de reconhecimento dos elementos que configuram a literariedade do texto. Na primeira, através da leitura, o leitor afirma sua personalidade, constrói um acervo de valores éticos e vivencia experiências e questionamentos pessoais. Na segunda, racionaliza o texto, dissecando-o na tentativa de identificar os vestígios do literário, no tempo e no espaço.

Do mesmo modo, Branco divide a leitura em dois tipos, a leitura de/da literatura, realizada pelo leitor amador e a leitura literária, concretizada pelo leitor especializado, vinculadas, respectivamente, à livre produção de sentidos legítimos e à decodificação "dos aspectos específicos dos textos em causa, em determinados contextos especializados" (BRANCO, 2008: 90-91).

Poslaniec e Houyel, citados por Faria (2005: 16), por sua vez, apresentam uma classificação tripartida: a comprometida (emotiva), que se aproxima da leitura comum; a leitura aprofundada (percepção dos fundamentos ideológicos do texto), que se afirma como um exercício de interpretação tendo como fundamentos os elementos extraliterários, e a leitura literária, caracterizada pela percepção dos processos composicionais do texto.

A questão que se coloca é a partir de quando e como estas leituras devem ser introduzidas no processo de escolarização. Evidentemente essas leituras não precisam estar necessariamente separadas, até mesmo porque quando lemos um texto literário, sempre estaremos introjetando um saber teórico-prático sobre os elementos que o especificam. Mesmo assim, acreditamos que, num primeiro momento, embora as duas dimensões do letramento literário ocorram, em alguma medida, simultaneamente, a escola precisa, nas séries do Ensino Fundamental, centrar seus esforços no sentido de criar o gosto pela leitura. Isso significa incentivar a fruição do texto, o prazer da leitura, o alargamento da sensibilidade, da imaginação, da criatividade.

A leitura que interessa ao primeiro nível do letramento (o prazer de ler) equivaleria à leitura comprometida, ou seja, aquela em que o leitor "deixa sua imaginação funcionar sem regras: concretamente, a leitura comprometida se traduz por uma identificação com as personagens, uma projeção na ação, uma espécie de diálogo permanente entre o livro e o leitor" (FARIA, 2005: 16).

Neste caso, não se deve

levar os alunos da escola fundamental a adquirir noções de teoria da literatura, mas de organizar o que Poslaniec chama de "pequenos saberes" que as crianças 
já possuem em seu contato diário com todo tipo de histórias que acontecem à sua volta: dos relatos de acontecimentos familiares aos vistos na tevê, que incluem não apenas os programas infantis e os desenhos animados, mas também os fatos do noticiário e reportagem dos jornais televisivos, cujos elementos básicos são geralmente organizados com a estrutura de narrativas. (FARIA, 2005: 21)

Podemos, então, concluir, que nesta primeira fase do letramento literário, as escolhas dos livros devem se pautar na diversidade, sem preconceito ou qualquer outro tipo de discriminação. É preciso considerar que se está trabalhando a sensibilidade, e sensibilidade ou senso estético é um construto cujo percurso e ritmo são únicos para cada pessoa. Respeitar isso significa aceitar todos os tipos de textos literários, desde que proporcionem prazer estético, ou seja, que deleite o leitor.

Mas, de um modo geral, quais as motivações levariam crianças e adolescentes a lerem? Segundo Zilberman (2003), é da relação com a realidade que surgem os elos entre leitor e obra. Para além de qualquer motivação exterior, há uma demanda interna que está ligada às necessidades existenciais desse público. Nesta mesma direção argumenta também Faria que "A valorização da leitura só pode se apoiar sobre a existência de interesses pessoais que encontram sua satisfação no ato de ler: éticos, práticos, profissionais, lúdicos" (FARIA, 1999: 103). Ou, nas palavras de Baudelot, citadas pela mesma autora, "O mundo do livro deve ser familiar para que o leitor possa fazer dele um caso pessoal" (FARIA, 1999: 104).

Entretanto, haveria de fato escolha livre? Cosson (2007: 31) e Versanini (2005: 32) afirmam que não, pois o leitor está sempre agindo sob influências e, quando é solicitado a escolher um livro literário, é influenciado pelos amigos, resenhas, propagandas, listas etc.

Numa experiência realizada com alunos do quinto semestre do Curso de Letras da UFT, foram distribuídos livros literários de diversas temáticas, entretanto todos com características de leituras apropriadas às quatro primeiras séries do Ensino Fundamental. Partindo do ponto de vista de que, independentemente da linguagem estar direcionada para o púbico infantil ou adulto, a obra de arte tem o poder de encantamento estético ao leitor, independentemente de sua faixa etária, foi solicitado que cada aluno escolhesse um livro e dissesse o motivo da escolha e se gostou da leitura, dentre outras questões. 
Os alunos deveriam fazer a leitura por prazer e, por isso, ficaram livres para mudarem de livro quando quisessem. Apenas dois estudantes, de um grupo de vinte e seis, quiseram trocar de livro, afirmando que o texto havia contrariado as expectativas criadas pelo título da obra.

A atividade foi realizada em sala de aula e já na observação dos semblantes dos alunos, enquanto faziam a leitura, pudemos perceber que alguns visivelmente demonstravam que a leitura lhes estava sendo agradável, que se deleitavam com o texto. Ao término da atividade, foi-lhes perguntado se alguém não havia gostado da leitura, ao que todos responderam negativamente. Foi-lhes perguntado também se alguém teve vontade de, ao ler o livro, mostrá-lo ao colega do lado, ao que três responderam positivamente. Estes, solicitados a contarem a estória que leram, o fizeram visivelmente com entusiasmo, mostrando que, apesar de a leitura não ser indicada para a faixa etária dos licenciandos, fruíram o texto, ou seja, experimentaram, de alguma forma, prazer estético numa leitura destinada a um público de no máximo nove anos.

$\mathrm{Na}$ seqüência, frisando que a leitura tinha como objetivo único a fruição estética, compreendido aqui como prazer estético, foi solicitado aos licenciandos que socializassem com os colegas os motivos das respectivas escolhas, ao que a maioria respondeu haver sido influenciada pelo título e pela ilustração da capa. Foram citadas também as seguintes motivações: o fato de já haver lido a estória quando criança, de ter um DVD em casa com o enredo do livro e de haver chegado atrasado e por isso escolheu pelo título e pelo número de páginas.

Os resultados acima nos levam a refletir sobre a validade dos motivos que levam à escolha das chamadas leituras livres. Se considerarmos que o objetivo do letramento literário nas séries do Ensino Fundamental é a criação do hábito da leitura pela experienciação do prazer de ler, a experiência nos leva a relativizar as palavras de Cosson (2007: 35), para quem as escolhas devem observar a diversidade, observando-se os níveis de complexidade, partindo do conhecido para o não conhecido.

Tal direcionamento pode ser válido na dimensão do letramento literário voltada para a racionalização dos aspectos composicionais do texto literário, o que se espera que ocorra no Ensino Médio, mas inadequado no Ensino Fundamental.

As respostas dos licenciandos nos levam também a reforçar as palavras de Azevedo (2005), para quem a divisão de livros por faixas etárias é artificial, sen- 
do mais uma invenção da escola e do que do literário em si. É preciso reforçar que, quando falamos de gosto, de prazer estético, falamos de categorias absolutamente relativas, cuja argamassa está vinculada à subjetividade, ao inconsciente, colocando em cena, no momento das escolhas, necessidades, desejos, expectativas, sensações etc.

Um bom texto literário, embora produzido para o público infantil, pode agradar ao leitor, independentemente de sua idade. Assim como as fábulas e os clássicos de Grimm eram leituras para adultos e hoje agradam crianças, também o que se pensa que é do universo da criança pode agradar aos adultos. A literatura desconhece, portanto, as divisões de faixa etária, pois ainda que os textos se diferenciem pela linguagem, todos eles apresentam, entretanto, um substrato atemporal, vinculado à sensibilidade, à imaginação e à criatividade, que pode dialogar com os leitores, independentemente de idade, época, local ou linguagem.

A experiência evidenciou também que, se o objetivo da leitura são o gosto, a fruição literária, a criação do hábito da leitura e a autonomia do leitor, todas as motivações, por menos ortodoxas que pareçam, são aceitáveis. Um aluno que não domina a leitura poderá até querer escolher um livro longo e mais complexo, mas muito provavelmente optará (e é desejável que assim seja) por um cujas letras sejam maiores, com maior número de ilustrações, enfim aquele que poderá ler sem dificuldades. Um licenciando poderá escolher um livro de pouca complexidade por querer apenas passar o tempo. O motivo não importa e, seja ele qual for, se leva à leitura prazerosa, é legítimo. Além do mais, as motivações exteriores (influência dos amigos, do título, das ilustrações) não são definidores de leituras por si mesmos. O fato de dois licenciandos haverem trocado de livro alegando que o enredo não atendeu à expectativa criada pelo título e pela ilustração da capa nos demonstra que as influências externas só são válidas enquanto desencadeadores de motivações internas, ligadas à subjetividade, à maturidade, carências e experiências dos leitores.

Outra constatação que a pesquisa nos mostrou é que, independentemente da idade, gostamos de reler, de ressignificar textos já conhecidos. Assim, só podemos aceitar como parcialmente verdadeira a afirmação de Cosson, para quem

[...] é necessário que o ensino da literatura efetive um movimento contínuo de leitura, partindo do conhecido para o desconhecido, do simples para o complexo, do semelhante para o diferente, com o objetivo de ampliar e consolidar 
o repertório cultural do aluno. Nesse caso, é importante ressaltar que tanto a seleção das obras quanto as práticas de sala de aula devem acompanhar esse movimento. (COSSON, 2007: 47-48)

Do mesmo modo, precisamos relativizar a afirmação de Branco, para quem a escola deve

contrariar tendências para a cristalização dos sujeitos em determinados procedimentos de leitura, de forma a habilitar os indivíduos para uma grande diversidade de modos de ler. Legitimar uma grande variedade de práticas de leitura de/da literatura não significa, contudo, confirmar o que o leitor já sabe ou aquilo em que ele se sente mais confortável. Pelo contrário, trata-se de o colocar em situação de experimentação múltipla e explícita, em processos auto e hetero-reflexivos. (BRANCO, 2008: 104)

Se falamos de gosto, de prazer estético, de formar o leitor apaixonado pela literatura, não devemos descartar a experiência da releitura, o prazer que as redescobertas de um texto já lido pode suscitar.

$\mathrm{O}$ mesmo motivo que leva os telespectadores da Globo a reverem suas novelas preferidas no horário vespertino e as crianças a exigirem, na fase anterior à escolarização, que os pais releiam indefinidamente a mesma estorinha sem que nenhum dado seja omitido (sob a fiscalização atenta da criança) levou alguns dos licenciandos a escolherem estórias que já conheciam pelo simples prazer de relê-las em uma outra linguagem. O mesmo motivo que direcionaram as suas escolhas também nos leva a nos decepcionarmos com as adaptações cinematográficas de obras literárias. Isso ocorre porque, no fundo, queremos experimentar novamente as mesmas sensações e emoções causadas pela leitura e na maioria das vezes negada pela versão cinematográfica. Todos estes fatos nos mostram que a formação do leitor se orienta por uma lógica que pode incluir a progressividade, mas jamais se reduz a ela.

Se considerarmos que, no Ensino Fundamental, o objetivo do letramento literário é criar o hábito da leitura e que este só vai ocorrer com a fruição estética (o deleite, o prazer da leitura), a escolha dos livros deve ser uma prerrogativa dos alunos, sempre que possível. Não está em jogo se os alunos leram este ou aquele livro, mas se eles leram com prazer o que se propuseram a ler. 
Não está em jogo se os alunos escolheram os livros por motivos "nobres", mas que, dentro das suas limitações, necessidades e desejos, conseguiram ler na íntegra e com prazer o que escolheram ler.

É preciso ter confiança no fato de que o cultivo do imaginário é uma necessidade básica do ser humano e, portanto, se a escola cria o espaço da leitura e se essa leitura é prazerosa, a formação do hábito de ler será uma conseqüência natural. Neste contexto, tão ou mais importante do que as leituras selecionadas pelos professores, para as quais Cosson (2007) aponta algumas estratégias interessantes de motivação, acompanhamento e avaliação, as leituras livres também precisam ser praticadas na escola, constituindo-se como potentes instrumentos para a formação do leitor. E é observando como essa prática se processa que teremos indicadores seguros para verificar se o aluno está sendo de fato letrado, autônomo em suas escolhas, lendo com paixão uma grande quantidade/variedade de obras literárias.

\section{Referências Bibliográficas}

AZEVEDO, Ricardo. A didatização e a precária divisão de pessoas em faixas etárias: dois fatores no processo de (não) formação de leitores. In: PAIVA, Aparecida et al. (Org.). Literatura e letramento: espaços, suportes e interfaces - o jogo do livro. Belo Horizonte, 2005, p. 75-86.

BRANCO, António. Da "leitura literária escolar" à "leitura escolar de/da literatura": poder e participação. In: PAIVA, Aparecida et al. (Org.). Leituras literárias: discursos transitivos. Belo Horizonte: Autêntica, 2008, p. 85-110.

CORRÊA, Hércules Toledo. Adolescentes leitores: eles ainda existem. In: PAIVA, Aparecida et al. (Org.). Literatura e letramento: espaços, suportes e interfaces - o jogo do livro. Belo Horizonte, 2005, p. 51-74.

COSSON, Rildo. Letramento literário: teoria e prática. São Paulo: Contexto, 2007.

FARIA, Maria Alice. Parâmetros curriculares e literatura. São Paulo: Contexto, 1999. . Como usar a literatura infantil na sala de aula. São Paulo: Contexto, 2005.

PEREIRA, M. A. Jogos de linguagem, redes de sentido: leituras literárias. In: PAIVA, Aparecida et al. (Org.). Literatura: saberes em movimento. Belo Horizonte: Autêntica, 2007.

RANGEL, E. O. Letramento literário e livro didático de língua portuguesa: os amores difíceis. In: PAIVA, Aparecida et al. (Org.). Literatura e letramento: espaços, suportes e interfaces - o jogo do livro. Belo Horizonte, 2005, p. 127-146. 
SOARES, Magda. Letramento: um tema em três gêneros. Belo Horizonte: Autêntica, 1998.

VERSANINI, Zélia. Escolhas literárias e julgamento e valor por leitores jovens. In:

PAIVA, Aparecida et al. (Org.). Literatura e letramento: espaços, suportes e interfaces - o jogo do livro. Belo Horizonte, 2005, p. 21-34.

ZILBERMAN, Regina. A literatura infantil na escola. São Paulo: Global, 2003. 